Fecha de recepción: julio 2020

Fecha de aprobación: octubre 2020

Fecha publicación: enero 2021

\section{El fin del príncipe azul: catálogos feministas para infancias diversas. El caso de la Colección Antiprincesas (Argentina)}

Daniela Szpilbarg ${ }^{(1)}$

Resumen: En los últimos años, el avance de los movimientos feministas en Argentina y el resto del mundo han generado importantes efectos en el campo editorial y literario, provocando la emergencia de editoriales y catálogos que problematizan los estereotipos de género en textos orientados a la infancia. El objetivo del artículo es relacionar la morfología editorial argentina y los textos centrados en las temáticas de género, considerando hipotéticamente que las editoriales consideradas "independientes" tuvieron un rol protagónico en la generación de propuestas editoriales no sexistas. Para esto, analizaremos por un lado el estudio de nuevas temáticas y catálogos, y por otro lado la historia y catálogo de la Colección Antiprincesas (Chirimbote) como ejemplo de esta tendencia.

Palabras clave: campo editorial argentino - feminismo - estereotipos de género - Colección Antiprincesas - infancias.

[Resúmenes en inglés y portugués en la página 243]

(1) Licenciada en Sociología. Doctora en Ciencias Sociales (UBA). Diploma de Estudios sobre Gestión Cultural y Políticas culturales. Docente de "Teoría Social Latinoamericana” (Facultad de Ciencias Sociales, UBA) y "Políticas de Edición y Traducción" (Maestría en Gestión de Lenguas, UNTREF). Investigadora asistente CONICET. Co-coordinadora del Programa "Mundo editorial, lectura y traducción desde los estudios de género(s) y feminismos" (CONICET-LICH-CEIECS- UNSAM) y del Programa de Estudios del Libro y la Edición (IDES).

\title{
Introducción
}

En los últimos años, la irrupción, avance y fortalecimiento de los movimientos feministas en Argentina y el resto del mundo han generado importantes efectos en el campo editorial y literario, provocando la emergencia de editoriales y catálogos que no solamente recuperan y producen teorías feministas, sino que también problematizan los estereotipos de gé- 
nero en diversos textos, algunos de ellos orientados a la infancia. El espacio de producción editorial argentino no solamente no es ajeno a los movimientos sociales vinculados con las demandas de mujeres y otras disidencias de género; por el contrario, refleja estas demandas cuando se encuentran en gestación en el tejido social y en muchos casos, circulan en formato escrito antes de que alcancen niveles de legitimación institucional.

El intercambio de textos supone una instancia de producción que expresa una capilaridad de fuerzas sociales que se corporizan en libros que, como un espejo, reflejan los debates sociales que se dan en el campo intelectual, social y político. Sin embargo, aunque se trata de esferas íntimamente vinculadas, los análisis del mundo editorial desde la perspectiva del género y las desigualdades de género han sido acciones poco realizadas hasta el momento ${ }^{1}$ pero es un tema crucial para poder establecer una historia del libro y la edición crítica, feminista procesual y totalizante, donde se analicen los libros, sus productores y los momentos de su producción como "campos" considerando a un tiempo aquello que un libro "dice", así como los efectos que provoca, retomando el concepto darntoniano del "efecto libro", y considerando además la importancia de los sujetos productores de la curaduría y publicación de esas ideas. Tomar una perspectiva feminista para registrar y estudiar el mundo del libro contemporáneo implica considerar el rol de las mujeres y otrxs editorxs, así como las políticas del lenguaje y las temáticas que subyacen en los materiales editados. De este modo, diversas teóricas han referido que para tener un posicionamiento feminista crítico, es preciso abordar "las relaciones entre sexualidades y textualidades, entre los géneros literarios y el género sexual" (Suárez Briones, 2002, p. 2)

El mundo del libro, entonces, se revela como una parte fundamental para analizar reflexivamente la explosión del movimiento de mujeres que se masificó a partir del año 2015. Lo cierto es que esta afirmación es correcta hasta un punto, ya que podría sostenerse con razón que los movimiento de mujeres y las teorías feministas existen desde la década del 70: lo acertado sería, entonces, hablar de un movimiento ya existente que, en Argentina, sedimentó a través de más de 35 años de Encuentros Nacionales de Mujeres ${ }^{2}$ durante los cuales se gestó también en Argentina un movimiento social, la Campaña por el Derecho al Aborto Legal, Seguro y gratuito hasta eclosionar y masificarse en la segunda década del siglo XXI, exigiendo leyes, algunas de las cuales fueron promulgadas, mientras que otras no. Estas luchas se dirigen no solo a reclamos por la igualdad entre los géneros o el reconocimiento de las disidencias sexuales, sino al reclamo por la aplicación de la Ley por la cual se vuelve obligatoria la enseñanza de la ESI (Educación Sexual integral) en las escuelas, Ley que no se aplica en su totalidad, y en algunos casos, directamente no se aplica ${ }^{3}$.

En relación con lo anterior, el objetivo del presente artículo es indagar los cruces entre el movimiento de mujeres y otras disidencias de género con los emprendimientos que producen materiales editoriales dirigidos a un público particular: las infancias. Sumado a esto, será preciso, previamente, relacionar la morfología editorial contemporánea argentina y los textos centrados en las temáticas de género, considerando hipotéticamente que las editoriales denominadas y consideradas "independientes" ostentan un rol protagónico en la generación de propuestas editoriales no sexistas para las infancias. Para esto, describiremos un caso emblemático de producción editorial no sexista contemporánea: el catálogo de la Colección Antiprincesas, tomando esta editorial y su catálogo como referente -junto con editoriales como la Cooperativa Muchas Nueces- de una constelación de proyectos 
que plasman el movimiento feminista y diverso orientado a la producción de libros para las infancias.

Haremos entonces un recorrido con una figura que encarna esos proyectos: Nadia Fink -integrante de la Editorial Chirimbote- considerando el hecho de ser en sus emprendimientos una figura múltiple: editora-autora-promotora-correctora, y esto es un punto central que nos permitirá reflexionar sobre la hipótesis del rol "militante" que esta editora tiene en estas transformaciones (contra) culturales, donde los libros expresan creencias, ideas y prácticas/modos de vivir.

Antes de recorrer esta trayectoria, presentaremos el panorama actual del mundo editorial argentino desde la perspectiva del feminismo crítico, plasmando una serie de dimensiones que exponen cómo en los últimos años se ha ido conformado y objetivando un espacio diferencial y asociado al mundo del libro que establece conexiones centrales con las demandas, reivindicaciones y avances en materia de feminismo y diversidad sexual, espacio desde donde es posible observar las relaciones entre feminismo, mundo editorial y sociedad. Este cruce es fundamental para centrar el foco en la producción de estereotipos en la sociedad, y específicamente en las infancias. En definitiva, a través de una metodología que combina la realización de observaciones participantes en Ferias, el análisis de catálogos y las entrevistas en profundidad, este texto pretende dejar registro de un momento epocal de efervescencia de demandas y cómo estas movilizaciones sociales tienen su correlato en el mundo de la producción de libros, tanto en el nivel de los catálogos como en los proyectos, constituyendo al mundo del libro una esfera insoslayable dentro de la militancia de los feminismos. El trabajo centrado en casos paradigmáticos de editores contemporáneos permite ver no sólo el lugar de la acción disidente de los editroxs en la esfera pública a partir de la generación de espacios de enunciación como ferias y festivales específicos, sino sobre todo ver las formas mediadoras a través de las cuales se alcanza a los públicos infantiles a través de la producción de libros. Los estudios de caso a partir del análisis biográfico y trayectorias permiten ver y reconstruir trayectorias centrando la mirada en la figura de un editor o editora en el sentido de que son curadores e ideólogos de sus proyectos culturales propios.

\section{La circulación internacional de ideas (feministas y diversas) y el rol de las pequeñas editoriales}

En Argentina, el 3 de junio de 2015 ocurrió un hecho que actualizó una nueva realidad en los feminismos. Esa jornada de lucha, en la que las mujeres llenaron la Plaza de los dos congresos en el centro de la Ciudad de Buenos Aires bajo la consigna \#NiUnaMenos, y se congregaron además en muchísimos puntos alrededor del país, "corporizó", como menciona Virginia Cano "el protagonismo y la legitimidad política que habían ido cobrando los movimientos feministas y socio-sexuales en los últimos años" (Cano, 2019, p. 12). Sin embargo, como reflexiona Malena Nijensohn, hay una complejidad en los movimientos feministas que radica en el hecho de que al tratarse de un movimiento diverso y plural, abre la pregunta por el tipo de feminismo que podría instaurarse a nivel político. 
La circulación de ideas sobre feminismos y género se pone en el tapete en un momento histórico específico, con más de 30 años de Encuentros Nacionales de Mujeres en Argentina, el surgimiento de las Marchas y colectiva \#Niunamenos en 2015, y las múltiples manifestaciones del movimiento de mujeres y otras diversidades de género. En este marco de luchas del movimiento de mujeres y visibilización de otras minorías sexuales, en 2010 y 2012 se promulgan en Argentina dos leyes centrales que marcaron la dirección de una época: el Matrimonio Igualitario y la Ley de Identidad de Género. Estas leyes supusieron la legitimación, y empoderamiento por vía de derechos legales de comunidades que habían sido históricamente muy castigadas. Las leyes, sin embargo, no significan que las personas trans o travestis tengan acceso igualitario al mercado de trabajo y otros beneficios sociales. Dentro del mundo del libro, este tipo de producciones confluyó con una voluntad de reivindicar el trabajo editorial hecho por mujeres, para mujeres: es decir, la visibilización de las mujeres editoras y producciones que en muchos casos reflexionan precisamente sobre la invisibilizacion de la mujer o su desigualdad y/o exclusión histórica dentro del mundo científico, artístico, y otros sistemas oficiales de acreditación en la sociedad patriarcal.

Para llevar adelante un registro del campo de producción de libros desde esta perspectiva, es preciso considerar la multiplicidad de feminismos existentes e incluso postular que hablar de editoriales $y$ feminismo implica no reducir el espectro de publicación a editoras mujeres que publican autoras mujeres o temáticas feministas, sino considerar todo contenido que sea escrito desde una pretensión de igualdad y diversidad, o bien de deconstrucción de las asignaciones habituales de los géneros. Esta perspectiva supone describir tanto la trayectoria de mujeres editoras, como de aquellos proyectos editoriales de orientación feminista, y/o diverso y de disidencia sexual en cuanto a sus materiales, independientemente de estar liderados por mujeres; e incluso abordar la emergencia de catálogos que como nunca antes ponen en escena las problemáticas que marcan la agenda de temas de la actualidad, como identidades de género, la violencia de género, los debates por la Ley que despenalice el aborto, las maternidades, la crianza, entre una multiplicidad de tópicos. Más allá de los proyectos editoriales que podemos analizar y considerar individualmente, en este apartado presentamos algunos indicadores concretos que expresan cómo en los últimos años, y posteriormente al año 2015, -en que eclosionó, como hemos visto, la demanda de los movimientos feministas-, surgen modalidades de presencia pública, institucional y/o colectiva de organizaciones e intervenciones feministas en el mundo del libro en Argentina, que se enlazan con modificaciones institucionales como la creación, por poner el ejemplo más emblemático, de un Ministerio de las Mujeres, Género y Diversidad en la actual gestión gubernamental de Alberto Fernández como presidente, desde diciembre de 2019. A la hora de plasmar una mirada de campo totalizante que involucre esta problemática, es preciso mencionar estas agrupaciones, acontecimientos e instituciones, para considerar estas situaciones como parte de un momento epocal en que el feminismo se encuentra muy imbricado en el espacio editorial. Algunos indicadores que objetivan este espacio son:

- La presencia de dos referentes mujeres y feministas como personalidades elegidas para brindar el discurso de apertura en la Feria del Libro de Buenos Aires, como Claudia Piñei- 
ro y Rita Segato en 2018 y 2019, cuyos discursos evidenciaron y expresaron demandas del movimiento de mujeres.

- La emergencia en 2018 de \#NosotrasProponemosLiteratura, un colectivo de escritoras y poetas organizado siguiendo la inspiración de \#Nosotrasproponemos en el sector de las trabajadoras de las artes visuales.

- La creación en 2018 del espacio "Orgullo y Prejuicio. Espacio de diversidad sexual y cultural" en la Feria del Libro de Buenos Aires, stand en el cual la Fundación El Libro otorgó un espacio específico para la exposición de materiales y charlas donde se discuten modelos de familia, identidades de género diversidad corporal y sexualidad. Desde la misma organización, se consideró como un objetivo poder "visibilizar la producción editorial, cultural y política de colectivos de disidencia sexual".

- El Stand colectivo Fuega en la Feria del Libro de 2019 (llamado oficialmente Fuego feminista conquista el espacio), donde confluyeron diez editoriales dirigidas o co-dirigidas por mujeres: El ojo de mármol, Presente, Nebliplateada, Pánico el pánico, Viajera, Paisanita, entre otras. Allí se reunieron algunas de las editoras del libro Martes verde $e^{4}$ y se propusieron visibilizar propuestas de distintos puntos del país.

- La creación de Ferias y eventos específicos con inmensa afluencia de público en la Ciudad de Buenos Aires, como la Feria del Libro Feminista (FILFEM), el Festival internacional del Libro de la Diversidad (FILDI), y el Festival Internacional de Arte Queer (FAQ), organizado por la Asociación Civil Brandon, que con sus diferencias en cuanto a las denominaciones (temática feminista, libro diverso desde el colectivo LGTTBIQ+ o queer) emergieron como espacios de encuentro entre editoriales, librerías, intelectuales, activistas, artistas, escritorxs e ilustradorxs vinculados a las temáticas feministas y de diversidad sexo-genérica.

- Las reuniones autoconvocadas de editorxs en la Librería La Coop y Feliza en 2017 y 2018, en las cuales se problematizó el rol de las mujeres como editoras, sus obstáculos, desafíos y la necesidad de generar espacios propios de visibilidad.

- La emergencia de publicaciones que tanto en colecciones de ensayo traducido como en la escritura propusieron intervenciones en el lenguaje convencional a través del uso de lenguaje inclusivo y no sexista, como por ejemplo en el marco de la Editorial Hekht y la editorial Ethos, que lanzó en 2018 una versión feminista y con lenguaje inclusivo de "El Principito".

- La aceptación, desde 2018, del uso del lenguaje inclusivo en distintas Universidades Nacionales para trabajos prácticos, exámenes y comunicaciones institucionales en los niveles de grado y posgrado, planteando una vinculación entre el lenguaje y el sexismo, y considerando -como planteaba la resolución de la Facultad de Ciencias Sociales de la Universidad de Buenos Aires- que "el lenguaje con el cual nos comunicamos y relacionamos comporta sentidos que reflejan desigualdades entre los géneros, naturalizando la segregación, discriminación o exclusión".

Resulta interesante destacar una cuestión vinculada a lo anterior: si bien los indicadores mencionados dan cuenta de que la presencia del feminismo se institucionalizó y en la actualidad se trata de una temática que es publicada preponderantemente por editoriales grandes y pequeñas, son las editoriales de nicho quienes primero publicaron y exploraron 
las tendencias en este sentido, tal como puede observarse si se estudian los catálogos de editoriales como Tinta Limón, Madreselva, Hekht o La mariposa y la iguana, editoriales argentinas que vienen publicando este tipo de temáticas desde hace muchos años.

Esto marca una diferencia fundamental y el motivo por el cual postulamos que los editores de pequeños sellos son quienes genuinamente investigan y crean catálogos de estas temáticas, encontrando en ellos y ellas la caracterización que Sophie Noel (2018) describió como un "editor crítico", aquel o aquella que no une el interés intelectual al interés comercial. No obstante, esto podía ser un recorrido interesante para pensar estas circulaciones de materiales en el mundo adulto. Pero lo llamativo es que el feminismo, las luchas por los derechos de las mujeres y demás minorías sexuales se ha revelado como un hito transgeneracional, y es eso precisamente lo que motivó que la oferta de materiales editoriales comenzara a mirar también el funcionamiento de la sociedad patriarcal y la producción de estereotipos que atraviesan lo que podríamos llamar el imaginario social patriarcal desde las infancias.

No son muchas las editoriales que son pioneras en la producción de materiales con este enfoque, pero dos son las que se destacan: Chirimbote y Muchas Nueces, a las cuales podríamos ubicar en un polo contracultural, vinculado a la cooperación, la autogestión y los movimientos sociales. Como hemos dicho, considerar algunos elementos de objetivación como los mencionados en un marco de análisis histórico y estructural permite comprender el funcionamiento de un campo editorial específico, el de la edición independiente en su rama feminista, y de este modo se ve una dimensión "a la vez intelectual y política que debe contemporizar con el mercado sin perder el valor simbólico fundador de su legitimidad" (Noel, 2018, p. 14).

Aquellos editores y editoras que se desarrollan en esta actividad tienen características que si bien no son nuevas, los emparentan con un tipo de editor vinculado a la edición de ciencias sociales y humanas y el libro político, particularmente en una intersección en que resulta "el libro feminista". Más allá de que sería apropiada una historización que abordara la publicación de estos materiales desde la década del 60 y 70, en que comenzó a popularizarse a nivel mundial, en este trabajo en particular nos enfocamos en el movimiento editorial de las primeras décadas del siglo XXI. En este sentido, si bien sería preciso extenderse en el tiempo, la pregunta central sería ¿Cuándo comienza un mercado del libro feminista? Y particularmente, ¿cuándo comienzan a surgir propuestas de feminismo y diversidad orientadas a las infancias como sujetos activos, y no solamente materiales que hablen sobre los procesos de identidad sexual de las infancias?

Puede postularse, entonces, que -vinculando lo anterior con elementos de distintas teorías de la circulación y recepción de ideas, como las de Horacio Tarcus (2013) o Pierre Bourdieu (2009) que analizan el uso y las derivas de conceptos en contextos distintos a los que fueron creados, considerando que se trata de un proceso complejo y no uniforme- es posible afirmar que hay editoriales que en el periodo presente encarnan luchas políticas por los derechos sexuales, y que han ejercido influencia en los movimientos de las minorías sexuales; y que esas luchas y protagonismo militante y teórico pueden observarse en los catálogos, en la producción teórica o en la importación y traducción de textos feministas. Más allá de esta consideración que hacemos para algunas editoriales de ensayo y ciencias sociales, en este artículo no desarrollaremos un análisis de la recepción de los textos de la 
editorial Chirimbote, ya que las publicaciones de corte feminista de materiales dirigidos a las infancias tienen una recepción que no es uniforme, y que depende de las resistencias y particularidades de las sociedades, así como de la acción de mediadores particulares. Entonces, volviendo al análisis de la segunda década del siglo XXI, podremos encontrar una serie de editoriales clave anteriormente mencionadas -Madreselva, Tinta Limón, El colectivo, Hekht, Sudestada, Muchas Nueces- que publicaron materiales fundamentales para comprender este periodo. No es casual que estas publicaciones emerjan en situaciones editoriales asociadas a las apuestas por crear una demanda que no existe, o como materiales que se derivan de colectivos editoriales que acompañan luchas sociales o movimientos sociales. De aquí que volvemos a rescatar aquello que Magalí Rabasa (2016) describía, en donde los libros subterráneos tejen y hacen también relaciones sociales, -incluso podríamos decir que los libros son relaciones sociales-, son la arena de ciertas luchas políticas, orgánicos en el sentido gramsciano de la palabra en tanto se constituye en cemento intelectual de movimientos y demandas de cambio social.

En relación con esto, una instancia interesante son las Ferias de Libros específicas, en este caso en particular la FILFEM, vigente desde 2018. Dicha Feria, en la que se encuentran las editoriales mencionadas, puede ser entendida como el espacio en el que se nuclean colectivos, artistas plásticos, publicaciones, referentes, debates, presentaciones y militancias. Reúne una cantidad de actores y por eso mismo se constituyó en un ritual que cristalizó el espacio del feminismo y la relación con los materiales impresos. Esta Feria, que comenzó en diciembre de 2018, llevó adelante cuatro ediciones, la última de ellas en el CCK en marzo de 2020, convirtiéndose en central por su carácter multitudinario y evento cultural donde además de exposición y venta de libros, fanzines, revistas e ilustraciones, se realizaron lecturas en vivo y paneles de especialistas, intelectuales y activistas. En 2019, participaron Dora Barrancos, Nora Cortiñas, Elizabeth Gómez Alcorta, Liliana Hendel, SaSa Testa, Lux Moreno, entre otrxs referentes del activismo, de la política y los derechos humanos. Desde la página web, se sostiene que esta feria surgió para "crear un espacio de encuentro entre la literatura y el feminismo", considerando que ambas instancias se potencian en la lucha por la igualdad de géneros.

Nos mueven las ganas de dar a conocer de forma masiva la gran cantidad de materiales que incomodan y desobedecen, que cuestionan las desigualdades existentes y que proponen otras maneras más equitativas de relacionarnos a partir de la praxis colectiva (Página web de la FILFEM).

La FILFEM condensa un espacio muy significativo que permite expresar en un evento el contenido y el tono de los reclamos sociales actuales del movimiento de mujeres y otras disidencias sexuales, al tiempo que pone en escena las temáticas y prolíficos trabajos vinculados a diversas temáticas relacionadas con la condición social de la mujer y las disidencias sexuales, al tiempo que postula una modificación en el estatuto de las infancias. Otra instancia importante son los ciclos de lectura que han surgido en los últimos tiempos y que pretenden retomar u homenajear a mujeres escritoras o poetas: "La doble voz", por ejemplo, organizado entre poetas y luego entre editoras; o el ciclo realizado en la librería Caburé donde en las "Veladas literarias" se propone ajusticiar el canon releyendo y 
visibilizando a escritoras que no fueron leídas como merecían y de este modo recuperar la propia tradición literaria escrita por mujeres. Este ciclo, organizado por Ana Ojeda y Jimena Néspolo, busca homenajear la escritura de mujeres como Sara Gallardo, Aurora Venturini, Silvina Ocampo, Fina Warschaver, entre otras, convocando a críticas y escritoras en actividad.

Antes de desarrollar el caso elegido, es importante destacar que tanto Fink como otros editores pueden ser considerados intelectuales en el sentido de los compromisos individuales y colectivos que llevan a cabo para promover una circulación social de las ideas a través de los libros. Como mencionaba Jean-Luc Nancy, la Idea platónica del libro designa la "entrega de una idea" (2016, p. 29), es decir que, como menciona este mismo autor, la dialogía es la esencia del libro: el libro se dirige a un interlocutor que será un lector. Es decir, si bien los editores no cumplen una función clásica de intelectuales, tienen acciones concretas de intervención a través de los catálogos, que en muchos casos engarzan con acciones de los intelectuales pertenecientes a las esferas de la acción política-gubernamental. Sin profundizar en esta reflexión -que podría extenderse en cuanto al rol de intelectuales que ostentan los y las editoras-, también la categoría de la internacionalización de los editores en tanto intelectuales podría ser un apropiado factor de análisis, ya que el proceso de la circulación internacional de ideas y textos vía la traducción y adopción de catálogos e importación de teorías, implica considerar los campos político y académico como campos de recepción de teorías que tienen además usos y consecuencias políticas en tanto organismos gubernamentales, proyectos de leyes y sanción de nuevas legislaciones. Para analizar estos discursos y su circulación, el abordaje metodológico tiene que atender a los textos y por otro lado las reflexiones de los agentes sobre su curaduría, sus producciones y la circulación de las mismas ${ }^{5}$.

\section{Nadia Fink. Una biografía editorial}

Nadia Fink es profesora, periodista y escritora. Fue redactora de la Revista Sudestada. En este trabajo interesa su actuación en Chirimbote, donde desarrolló las colecciones de Antiprincesas y Antihéroes, en las cuales trabaja con un diseñador y un ilustrador. La colección Antiprincesas aborda distintos personajes históricos reales, de distintos campos de acción, desde la política, a la música o la pintura. Las figuras principales que constituyen el catálogo de los libros de esta colección son Frida Kalho (México); Clarice Lispector (Brasil), Juana Azurduy, Evita (Argentina), Violeta Parra (Chile), las Madres de Plaza de Mayo (Argentina); Alfonsina Storni (Argentina), entre otras; es decir, la colección retrata mujeres reales de la historia.

En una entrevista, Fink mencionaba que la motivación para la colección Antiprincesas comenzó en el año 1996, después de recibirse de Profesora de Educación inicial. Cuenta que tenía una "discusión interna" con los cuentos clásicos, respecto de la "quietud" que observaba en las mujeres de los cuentos clásicos. Luego, durante la crianza de su hija, relata que intentó acercarle otros materiales diferentes, ya que "la pulcritud y la quietud de los personajes me parecían aterradores como modelo para las mujeres". 


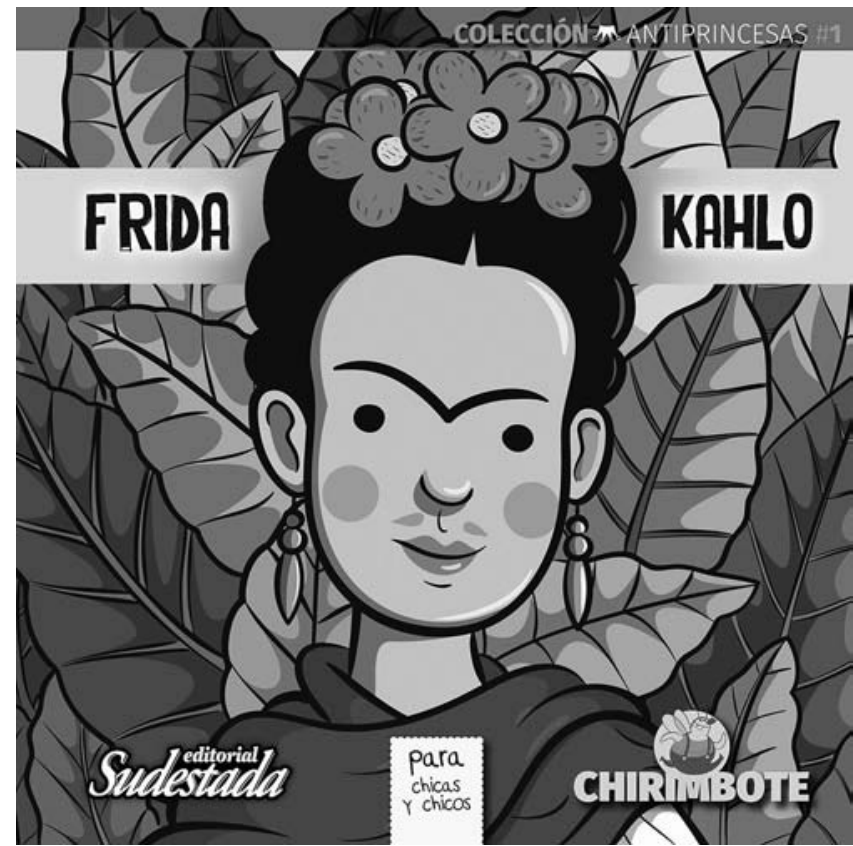

Figura 1. Fuente: Página web de Chirimbote.

Luego incursionó en el periodismo con otros compañeros y fue tejiendo una mirada con otras perspectivas de clase y de género, que hicieron que en algún momento las notas y biografías que se publicaban para adultos pudieran ser materiales para infancias. Fink considera que en ese proceso de romper con estereotipos que venían dados en juegos, juguetes o películas, una "literatura feminista" le parecía un espacio "necesario y poco transitado". Como parte de la base ideológica de la editorial -en la que Fink se reconoce como autora, editora principal y productora- sostiene que veía una "falta":

Íbamos mucho a los kioskos de diarios, y veíamos que había una oferta "alternativa” para adultos y adolescentes, pero no había de ninguna manera para niñes. Tenías Disney, la revista Jardincito, los autitos de colección, la lonchera a principio de año, y no mucho más. Creo que ahí sentimos que estaba faltando (Comunicación personal, 2020).

En numerosas ocasiones Fink sostuvo que la colección nace para postular otros modelos frente a la idea de "princesa" de los cuentos tradicionales y de hadas para niños y niñas, que luego son retomados por la industria cinematográfica. Asimismo, la creadora considera que las producciones culturales "atrapan" a los niños y niñas desde la infancia, y la 
colección aparece como un modo de ir de la mano con la lucha feminista proponiendo otros modelos femeninos, determinando y señalando una propuesta de lectura que fue recibida de manera positiva y masiva por el público. La idea de "atrapar" mencionada por Fink expresa una connotación tanto normativa como represiva: los estereotipos de género, tema que desarrolla Virginie Despentes en su famoso trabajo Teoría King Kong, son el cemento de un sistema organizado según la dinámica patriarcal en que las niñas -futuras mujeres- se acomodan en el lugar de "lo femenino" reprimiendo su poder y su potencia y desplegando su feminidad legítima en el mercado de relaciones sociales estereotipadas según lo "permitido" para cada género. De esta manera se rescata su rol como "editora" en el sentido de ser "creadora de un canon" (Fernández, 2019, p. 13) que al mismo tiempo propulsa relaciones sociales contrahegemónicas al subvertir los estereotipos de género en los materiales editados.

\section{La colección Antiprincesas}

La colección se presenta en su página web con una imagen: se observa en un campo a Violeta Parra tocando la guitarra, conversando con Juana Azurduy y Frida Kalho. De esta manera, a través de un epígrafe, se sostiene que siempre hubo "mujeres libres e independientes y grandes artistas latinoamericanos", luego caracterizadas como "heroínas de carne y hueso" (página web de Chirimbote).

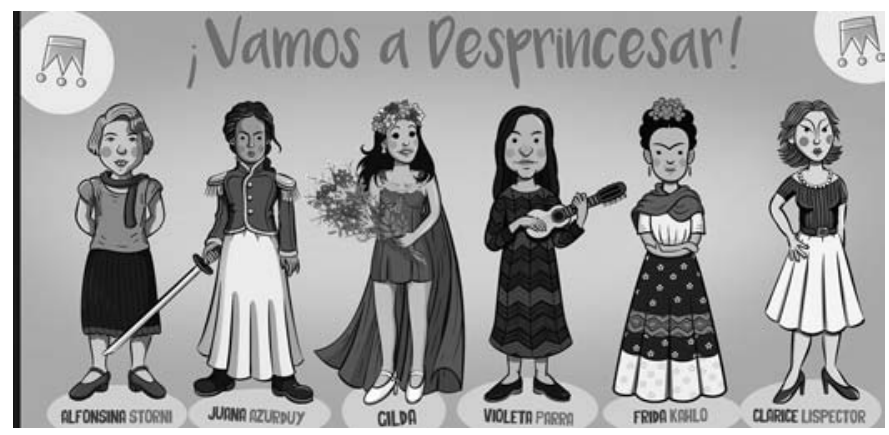

Figura 2. Fragmento página web de Chirimbote.

La primera publicación comenzó con una investigación sobre Frida Kalho que Fink había realizado para Sudestada y que consideró que era un personaje interesante para explorar en pos de construir el retrato de una mujer que no respondía al clásico estereotipo. Según la editora y autora, la publicación del libro de Frida fue muy importante y significó una 
"colaboración a la ruptura que se venía haciendo a la batalla cultural". Sumado a eso, la salida del libro de Violeta Parra fue también en un momento clave, en junio de 2015, en ocasión del primer \#Niunamenos.

Esta colección, si bien se compone de relatos breves biográficos de distintas mujeres reales, está estructurada como "historias", vinculadas a la estructura del cuento. El cuento es considerado por Fink una herramienta de aprendizaje y de transmisión de valores, prejuicios y estereotipos. Cuando refiere a los personajes de los cuentos infantiles de princesas, Fink destaca que se trata de princesas "ricas, bondadosas y sumisas", y que esa caracterización va generando formas de autopercibirse y actuar en las infancias. De esta manera, la propuesta que se desliza desde los materiales de Chirimbote se orienta a "romper" los estereotipos hegemónicos de belleza y quehacer de las mujeres a partir de la exposición de otros modelos.

Por eso en la entrevista afirma que la colección fue pensada como una "alternativa" ante los cuentos clásicos, considerando que los mismos contienen mensajes implícitos que influyen en los pensamientos y acciones, pero se siguen relatando porque resultan en apariencia "inocentes". Según ella, lo "anti” del nombre de la colección no significa "oponerse" a las princesas, sino ofrecer a las infancias otros modelos de mujer: considerando que contar la vida y el legado de mujeres fundamentales en nuestra historia les daba a las niñas (y niños) una perspectiva diferente de ser mujeres. Resulta significativo pensar que la colección Antiprincesas, en la que hemos puesto el foco, funciona como un ámbito donde mujeres de distintas procedencias nacionales, se hermanan en un catálogo común, donde comparten el hecho de ser mujeres "populares" y rupturistas, de los moldes familiares y de la sociedad.

La propuesta de la colección es que todas sean mujeres latinoamericanas porque es una oposición a los cuentos clásicos que siempre nos mostraron a estas princesas de una cultura muy europea, lejana a las chicas de hoy. Nosotros pensamos que esto de las Antiprincesas no tiene tanto que ver con 'romper', o 'que desaparezcan las princesas', sino con que haya espejos nuevos, o más reales, donde puedan mirarse (Entrevista a Fink, realizada en el Programa Caminos de Tiza, TVPública).

Los textos-biografías que componen la colección cuentan con una proporción a página completa de ilustraciones que acompañan los textos, un abordaje fantasioso de las vidas reales, en el que en varios casos aparecen personajes ficcionales que "introducen" los hechos de la historia, como un "perro preguntón" en el caso del libro sobre Clarice Lispector, y una intención didáctica, ya que hay una cantidad de términos y conceptos muy complejos que dan cuenta de que se intenta transmitir explicaciones, como el caso de "revolución", "surrealismo" o "colonias", si tomamos como referencia algunos de los que aparecen en las biografías de Frida Kalho o Juana Azurduy, que junto a Violeta Parra y Clarice Lispector son las figuras "antiprincesas" principales. Esta colección rescata las características y los valores de mujeres comunes (pero también de hombres en la colección Antihéroes), que decidieron seguir sus propias reglas y lucharon por ideales y convicciones distanciándose, como recatan Morales y Piantoni (2016) de lo que sería la representación 
del "legado patriarcal y religioso que América Latina heredó de sus conquistadores". Otra característica formal que comparten los distintos textos es que al terminar la biografía, hay un apartado donde se proponen actividades lúdicas y de aprendizaje para recuperar los hechos leídos.

Esto nos lleva al otro elemento central de los libros de esta colección: la importancia de la figura del adulto mediador -en tanto familiar o docente- es fundamental en los dos casos analizados, ya que permite que los niñxs contextualicen esos personajes en los momentos en que vivieron. Dentro de la historia de Chirimbote, algunos de los hitos que menciona Fink es haber podido constituirse como cooperativa y haber podido participar de la Feria del Libro de Buenos Aires con un stand de Infancias Libres.

\section{Un catálogo feminista y LGTTB: de la ESI a la despenalización del aborto y las infancias trans}

El catálogo de Chirimbote es amplio y su editora lo define como "muy diverso". Además de la Colección Antiprincesas, que cuenta al momento del trabajo con 16 títulos, el catalogo se presenta organizado en torno a cuatro grandes ejes: Antiprincesas- Antihéroes- Educación en Géneros e Infancias libres.

El catálogo de Chirimbote atraviesa transversalmente la niñez pero vista desde varios puntos de vista: no solo para infancias, sino también para personas grandes que se dedican a crianza, acompañamiento y están alrededor de niñes. Y tratamos de que sea lo más diverso posible, en cuanto a diversidad sexual, de clases, razas, religiones. Hace un tiempo sacamos un libro que se llama "Soy Galo", que es la historia de Galo, que tiene síndrome de Down, y está ilustrado por él. Ahí trabajamos con su psicopedagoga y con su familia (Comunicación personal, 2020).

La denominación de las distintas colecciones da cuenta de la orientación ideológica de la editorial, en el sentido de que se aboga por una aplicación de la Ley de Educación Sexual Integral en la educación, así como se defiende la Ley de Identidad de Género, y el proyecto de Ley para la despenalización del aborto. Si bien Chirimbote como proyecto se visibilizó masivamente a partir de la Colección Antiprincesas, hay materiales que refieren a las temáticas de la Ley del Aborto (Será Ley, o \#Niunamenos desde los primeros años Educación en géneros para infancias más libres), la contaminación de los suelos con Glifosato, e incluso a la Ley de ESI -antes mencionada-, a través del libro coeditado con Las Juanas y escrito en coautoría entre Fink y Cecilia Merchán, Diputada del Parlasur y Diputada Nacional en el período 2007-2011, en el cual impulsó Leyes como la del Matrimonio Igualitario y la Identidad de Género. Fink, además, compiló el libro Infancias Libres. Talleres y actividades para la educación en géneros. En cuanto a los libros referidos a este tema, podemos mencionar también Todas las infancias, todos los colores, o Pendeja. Diario de una adolescentes trans. En cuanto al cupo trava-trans del catálogo considera a la editorial "Muchas nueces" 
como un "faro en materia de inclusión" y el antecedente de cupo trans en relación a materiales ${ }^{6}$. Volviendo a su caracterización del catálogo, en la entrevista mencionó que los libros son pedidos en las escuelas como material de lectura: una práctica no institucional ni oficial, sino que se produce a través de contactos con directores y docentes.

Como mencionan en otros libros de la misma editorial, las niñas a las que se dirigía la colección analizada fueron creciendo, junto con el paso del tiempo y las discusiones y las conceptualizaciones respecto del rol de la mujer, que se continúan en los materiales producidos. Así, en 2019 se publicó Antiespejito. Guía para ser una Antiprincesa, donde se retoman y reflejan muchos conceptos de la lucha actual del feminismo, como por ejemplo la idea de "sororidad" y diversidad sexual. La particularidad a destacar también -si bien no es tema de estudio específico de este artículo- es el uso de lenguaje inclusivo, un debate que se dio en torno a la ideología patriarcal implícita que existe en el uso del lenguaje convencional.

\section{Conclusiones: libros para acompañar y proteger infancias}

Hemos reflexionado sobre la relación entre editores en tanto intelectuales y mundo social, campo político e intelectual. Nos hemos centrado en la figura de una autora-editora como Nadia Fink, tomando en consideración que los libros tienen como esencia la comunicación, la resonancia y la diseminación de ideas. Hemos analizado una cooperativa editorial como Chirimbote que ha masificado una colección que propone una ruptura con los estereotipos clásicos del ser mujer. En consecuencia, la colección analizada ofrece otra mirada, permitiendo plasmar una descripción del ser mujer a partir de características habilitantes en las niñas que se acercan a la lectura. Esta "visión propedéutica" de las "antiprincesas" postula un canal de resignificación entre el mundo y lenguaje de los adultos/as y el de los niños y niñas (Morales y Piantoni, 2016), que vuelve a este proyecto disruptivo en la forma de instalar la discusión sobre los estereotipos de la mujer, pero también de los formatos de familia monogámica.

Finalmente, vincular esta editorial y esta colección con la recepción de las teorías de género en Argentina es un punto significativo, ya que permite observar cómo la circulación de ideas y teorías feministas y post feministas impacta también en la producción de materiales para las infancias que discuten los materiales existentes hasta ese momento, generando efectos disruptivos. Así, siguiendo a Vacarezza, en la primera mitad de la década del 2000 fue fundamental el ingreso de los textos de Judith Butler sobre género, que junto con los de otras feministas postestructuralistas:

...comenzaron a conmocionar un campo de estudios académicos y acción política que en Argentina, desde la segunda mitad de la década del 1980 comenzaba a estabilizarse en torno a ciertos conceptos e identidades políticas ("género" y "mujeres", principalmente). Las críticas "post" se dirigían tanto hacia la fijeza esencialista del sujeto presupuesto por las teorías y las prácticas feministas, como a la rigidez de los marcos binarios que, hasta entonces, habían susten- 
tado las reflexiones sobre el género, el cuerpo y la identidad (Vacarezza, 2017, p. 1260).

Un punto importante a destacar también como cierre de este artículo exploratorio es aquel que vincula la morfología del campo editorial con el rol que editores y editoras han tenido en estas publicaciones, reclamos y transformaciones. En este sentido, recorriendo las principales editoriales que históricamente tomaron la iniciativa en la publicación de estas temáticas, el sector de la edición independiente es pionero, con editoriales como Tinta Limón, La mariposa y la iguana, Milena Caserola, Muchas Nueces o Madreselva, en la publicación de libros sobre temáticas de feminismo, diversidad sexual, así como autorxs trans y progresivamente otras editoriales fueron orientándose a estos materiales al aumentar la demanda.

De este modo, las prácticas de los editores independientes "diversxs" vinculados a la publicación de materiales feministas, disidentes o diversos tendientes a performar, producir y enriquecer lo que podríamos llamar una bibliodiversidad genérica cobran densidad y emergen como procesos relacionados con un momento histórico particular, pero también con la concentración del sector editorial, expresando cómo las editoriales independientes están vinculadas a la vanguardia y a las publicaciones que ocurren cuando los fenómenos sociales y políticos están "vivos", o latentes como reclamos en la sociedad, mientras que las editoriales de gran escala en muchos casos se suman al fenómeno editorial cuando ya se encuentra instalado y masificado. Es decir, es posible postular la hipótesis de que los pequeños emprendimientos editoriales, muchas veces militantes, pasan, como es el caso de Chirimbote, de reproducir ideologías a producir ideología que contribuye a postular nuevos imaginarios sociales y culturales en relación con los estereotipos de género.

El caso analizado es uno, pero es representante de una constelación de editoriales afines que están comenzando esta tarea de publicar materiales LGTB tendientes a "proteger a las infancias diversas", como mencionaba Gonzalo Miranda, de la Cooperativa Muchas nueces, postulando que, además, los libros publicados son por un lado efecto de una planificación y por otro producto de los encuentros, lo cual marca el carácter de espontaneidad y vitalidad de los materiales publicados que mencionábamos antes y que es característico de la dinámica de las pequeñas editoriales. En el caso de Muchas nueces, Miranda menciona que si bien hay temáticas o situaciones muy complicados para las infancias- como la desocupación, las infancias trans o las situaciones de prostitución- las infancias son capaces de absorber esas temáticas que las atraviesan en la vida cotidiana. En el caso de esta editorial, inspirados en la experiencia de la editorial Rompan Filas, ellos se plantearon que en el siglo XXI debían "usar esa experiencia para ampliar y demandar más democracia", planteando contenidos, por ejemplo, para las infancias trans. Esta editorial, que trabaja y coedita algunos materiales con Chirimbote, organiza desde 2018 el FeNiA (Festival de la Niñez Abrazada).

El caso de la Colección Antiprincesas, descripto en particular en este artículo, y junto a otras editoriales que hemos mencionado, coinciden en un punto: y es el de otorgar a las infancias su importancia central como sujetxs activxs. El grupo de estas editoriales analizadas permite ver un circuito de producción y de intercambio de ideas y obras, una constelación cultural de la actualidad, cuyos objetivos se reúnen en ciertas obras que funcionan 
como una suerte de "manifiestos". Esto se relaciona con el hecho de que las ideas circulan en la sociedad pero hacen fuerte mella en la constitución de identidades: es en la infancia en donde se despliega la construcción y la asunción de personalidades estereotipadas, y es allí donde las editoriales que consideran a las infancias sujetxs activxs ofrecen materiales tanto para niñxs como para adultxs que, siendo mediadores en la lectura, puedan dar una nueva mirada.

\section{Notas}

1. En este campo, los avances más fuertes se han dado en la sociología de la traducción, mientras que en la historia y la sociología del libro no hay tanta producción en cuanto a los estudios sobre el rol de la mujer, aunque en los últimos años comenzó a haber grandes avances y producciones bibliográficas en esa dirección.

2. El Encuentro Nacional de Mujeres (ENM) se realiza en Argentina anualmente desde mediados de la década de 1980. Se realizó por primera vez en 1986, a partir de la iniciativa de un grupo de mujeres, que el año anterior habían asistido a la III Conferencia Mundial de Mujeres de Nairobi (Kenya, África). Es un espacio autónomo, auto-convocado, democrático y federal, que se realiza en distintas ciudades del país cada año. En cada encuentro, se propone de manera plural un temario para los talleres que puede ser ampliado con las propuestas de las participantes. Al final de cada encuentro, se define el lugar en que se realizará la siguiente edición y se lee el documento resultante del trabajo en los talleres.

3. La educación sexual integral (ESI) es un derecho de niños, niñas y adolescentes contenido desde la sanción de la Ley 26.150 que se sancionó en 2006 y que obliga al Estado Nacional a crear el Programa de Educación Sexual Integral. Esto no refiere un contenido o asignatura específica, sino un espacio de saberes que forme parte del proyecto educativo de la escuela.

4. Martes verde es una antología poética de alrededor de 50 poetas, que se leyó los días martes frente al Congreso durante las reuniones informativas durante el debate por la Ley de despenalización del Aborto en 2018 antes de que saliera la media sanción por el derecho al Aborto Legal.

5. Para ahondar en las reflexiones sobre los intelectuales, la internacionalización y la profesionalización, véase Sapiro, Gisele: Los intelectuales: profesionalización, politización, internacionalización, 2017, Eduvim.

6. Muchas Nueces es una Cooperativa editorial surgida en 2012 fundada por diez integrantes de distintas procedencias profesionales, que se conocieron en un Diplomado en Gestión autónoma de los medios sociales de comunicación en La vaca. Tienen un catálogo que fue desarrollándose escalonadamente, a razón de 4 o 5 libros por año, configurando un total de aproximadamente 18 títulos, entre los que se destacan Crianzas, de Susy Shock, La Princesa Guerrera, de Amalia Boselli y Travesti. Una teoría lo suficientemente buena, de Marlene Wayar. 


\section{Referencias bibliográficas}

Beltramo, A. (2019) "Nosotras proponemos literatura. Compromiso y praxis. Entrevista a Cecilia Szperling”, AAVV, Feminismos insurgentes, Buenos Aires: Milena Caserola. (pp. 311-326).

Bidaseca, K. et al (comp.) Feminismos insurgentes, Buenos Aires: Milena Caserola.

Bourdieu, P. (2009). Intelectuales, política y poder. Buenos Aires: EUDEBA.

Butler, J. (1990). Gender Trouble: Feminism and the Subversion of Identity. London/New York: Routledge

Castro Vázquez, O. (2008). “Género y traducción: elementos discursivos para una reescritura feminista”. En: Lectora, 14, pp. 285-301.

Chollet, M. (2019), Brujas. La potencia indómita de las mujeres, Buenos Aires: Hekht.

Corbelli, J., "El mundo del libro hecho por mujeres ingresa a la Historia" Diario Tiempo Argentino 17/4/2018. Disponible en: https://www.tiempoar.com.ar/nota/el-mundo-dellibro-hecho-por-mujeres-ingresa-a-la-historia

De Sagastizábal, L. y Quevedo, L. (2015). Optimistas seriales. Conversaciones con editores. Buenos Aires: EUDEBA.

Fernández, P. (2018). "La condición de autoría femenina: el caso de Emilia Serrano, Baronesa de Wilson, y la polémica con George Sand y Alphonse de Lamartine (1859)”. En Lluch-Prats, J. (ed.) Entresiglos: del siglo XVIII al XIX. Estudios en homenaje al profesor Joan Oleza, pp. 49-65.

Fernández, P. (2019). vol 25 (2019) Pura Fernández “¿Una empresa de mujeres? Editoras iberoamericanas contemporáneas", Lectora. Revista de Dones y textualitat, Universitat de Barcelona, pp. 11-39.

Morales, M. y Piantoni, G. (2016), “Colección Antiprincesas+Antihéroes”, en La aljaba. Segunda época, Vol. XX, página 271-274.

Nancy, J. (2016). Sobre el comercio de los pensamientos. Buenos Aires: La marca editora.

Nijensohn M. (2019). La razón feminista. Buenos Aires: Cuarenta Ríos.

Schwartz, R. (2014). "Las ideas fuera de lugar". Meridional. Revista chilena de estudios latinoamericanos, n. 3, p. 183-199.

Sorá, G. (2003). Traducir el Brasil. Una antropología de la circulación internacional de ideas, Buenos Aires: Libros del Zorzal.

Suárez Briones, B. (2003). "Introducción. Teorías literarias feministas. (Con)Textos”. Sextualidades: teorías literarias feministas, pp. 1-42. Alcalá de Henares: Ayuntamiento de Alcalá de Henares, Centro Asesor de la Mujer.

Szpilbarg, D. (2019). "La editora feminista". En Cartografía argentina de la edición mundializada: modos de hacer y pensar el libro en el siglo XXI, 211-219. Temperley: Tren en Movimiento.

Szpilbarg, D. (2018). “Armas cargadas de futuro: hacia una historia feminista de la edición en Argentina”. En Malisia no 5, agosto. Dossier “Mujeres y Edición”, p. 15-29.

Tarcus, H. (2013). "El marxismo en América Latina y la problemática de la recepción transnacional de las ideas". Temas De Nuestra América. Revista De Estudios Latinoamericanos, 29 (54), 35-86. Recuperado de https://www.revistas.una.ac.cr/index.php/tdna/ article/view/6342 
Vacarezza, N. (2017). "Judith Butler en Argentina. Recepción y polémicas en torno a la teoría de la performatividad del género". Revista Estudos Feministas, vol.25, n.3, pp.1257-1276. https://doi.org/10.1590/1806-9584.2017v25n3p1257.

Valencia, M. y Marin, P. (2019). Ellas editan. Testimonios de dieciséis editoras. Colombia: Editorial Ariel.

Von Flotow, L. (2018) "Feminism, gender and translation", in D'hulst, L. \& Gambier, Y. (Eds.) A history of modern Translation knolewdge. Sources, concepts, effects, Amsterdam: John Benjamins, pp. 347-352.

\begin{abstract}
In recent years, the advance of feminist movements in Argentina and the rest of the world have generated important effects in the publishing and literary field, causing the emergence of publishers and catalogs that problematize gender stereotypes in childhoodoriented texts. The objective of the article is to relate the editorial morphology of Argentina and the texts focused on gender issues, hypothetically considering that publishers considered "independent" had a leading role in generating non-sexist editorial proposals. For this, we will analyze on the one hand the study of new themes and catalogs, and on the other hand the history and catalog of the Antiprincesas Collection (Chirimbote) as example of this trend.
\end{abstract}

Keywords: Argentinian publishing field - feminism- gender stereotypes - childhood Colección Antiprincesas.

Resumo: Nos últimos anos, o avanço dos movimentos feministas na Argentina e no resto do mundo gerou efeitos importantes no campo editorial e literário, causando o surgimento de editoras e catálogos que problematizam estereótipos de gênero em textos voltados para a infância. O objetivo do artigo é relacionar a morfologia editorial da Argentina e os textos focados em questões de gênero, considerando hipoteticamente que os editores considerados "independentes" tiveram um papel de liderança na geração de propostas editoriais não sexistas. Para isso, analisaremos, por um lado, o estudo de novos temas e catálogos e, por outro, a história e o catálogo da Coleção Antiprincesas (Chirimbote) como exemplo dessa tendência.

Palavras chave: campo editorial argentino - infancia - estéreotipo de genero - Colección Antiprincesas.

[Las traducciones de los abstracts fueron supervisadas por el autor de cada artículo] 